\title{
Margaret McCartney: Honesty, placebos, and pain care
}

\author{
Margaret McCartney general practitioner, Glasgow
}

The medicine cabinet for chronic pain is-let's face it-poor. At the bottom of the ladder is paracetamol: ineffective for low back pain and, in the long term, for osteoarthritis. ${ }^{1}$ Observational data have linked the increased use of paracetamol to cardiovascular, renal, and gastrointestinal side effects and overall mortality. ${ }^{2}$

Even topical anti-inflammatories do not avoid the well known side effects of gastric irritation and bleeding. ${ }^{34}$ Oral non-steroidal anti-inflammatory drugs (NSAIDs) are worse. Diclofenac, in particular, raises the risk of myocardial infarction by about 3 in 1000 medium risk people who have it prescribed. In people at high risk, diclofenac increases this risk by 7-8 in 1000. That's a similar increase in risk as with cyclo-oxygenase- 2 inhibitors, ${ }^{4}$ such as rofecoxib (Vioxx). And, although naproxen is safer in this regard, all NSAIDs increase gastric side effects ${ }^{5}$ - and non-aspirin, non-steroidal anti-inflammatory use is implicated in $12 \%$ of hospital admissions caused by adverse drug reactions. ${ }^{6}$ There's also renal impairment, as well as the risks to people with hypertension.?

Co-codamol is only slightly better than paracetamol alone. ${ }^{8}$ Amitriptyline is cheap and often useful, but it comes with the risk of anticholinergic side effects. ${ }^{9}{ }^{10}$ Gabapentin use has soared: 8.2 million prescriptions were generated in England alone in 2013, a 46\% rise from 2011. Popular for neuropathic pain and fibromyalgia, gabapentin is associated with euphoria and has become a drug of misuse. ${ }^{11}$ Just over a third of people using gabapentin for chronic pain will report a reduction of $50 \%$ or more. $^{12}$

All active drugs, of course, come with side effects. We're encouraged to treat pain seriously and generously, but chronic pain differs from terminal care. How sure are we about these drugs in the long term? And does the relentless political focus on the "happy customer" model of NHS delivery mean that doctors are less inclined to be unpopular by refusing to escalate or continue doses of drugs that barely help? Is the customer always right when it comes to high and sustained doses of drugs that have addictive qualities?

The Cochrane Collaboration found that $35 \%$ of patients reported pain to be at least halved by gabapentin-but so did $21 \%$ of people taking a placebo. We also know that honest description does not necessarily preclude the placebo effect. ${ }^{13}$ Simple things such as tablet colour can generate beneficial physical responses but are understudied. ${ }^{14}$

It's easy to prescribe active drugs that often don't work, but it should be easier to prescribe non-drug alternatives. Often neither I nor my patient is reasonably sure that the drug being taken for chronic pain is useful. It should be easier to find this out. We need carefully packaged and coloured placebos to be used—without deception—as n=1 trials. And, if we had enough physiotherapists and psychologists working with GPs in primary care, we may well do less harm.

Competing interests: I have read and understood the BMJ policy on declaration of interests and declare the following interests: I'm an NHS GP partner, with income partly dependent on Quality and Outcomes Framework points. I've written two books and earn from broadcast and written freelance journalism. I'm an unpaid patron of Healthwatch. I make a monthly donation to Keep Our NHS Public. I'm a member of Medact. I'm occasionally paid for time, travel, and accommodation to give talks or have locum fees paid to allow me to give talks but never for any drug or public relations company. I was elected to the national council of the Royal College of General Practitioners in 2013 and am chair of its standing group on overdiagnosis. I have invested a small amount of money in a social enterprise, Who Made Your Pants?

Provenance and peer review: Commissioned; externally peer reviewed. Follow Margaret on Twitter, @mgtmccartney

1 Machado GC, Maher CG, Ferreira PH, et al. Efficacy and safety of paracetamol for spinal pain and osteoarthritis: systematic review and meta-analysis of randomised placebo controlled trials. BMJ 2015;350:h1225.

2 Roberts E, Delgado Nunes V, Buckner S, et al. Paracetamol: not as safe as we thought? A systematic literature review of observational studies. Ann Rheum Dis 2015; doi:10.1136/ annrheumdis-2014-206914.

3 Makris UE, Kohler MJ, Fraenkel L. Adverse effects of topical nonsteroidal antiinflammatory drugs in older adults with osteoarthritis: a systematic literature review. J Rheumato 2010;37:1236-43.

4 European Medicines Agency. New safety advice for diclofenac-CMDh endorses PRAC recommendation. 28 Jun 2013. http:///bit.ly/1MKyT6t.

5 Coxib and Traditional NSAID Trialists' (CNT) Collaboration, Bhala N, Emberson J, et al. Vascular and upper gastrointestinal effects of non-steroidal anti-inflammatory drugs: meta-analysis of individual participant data from randomised trials. Lancet 2013;382:769-79.

6 Pirmohamed M, James S, Meakin S, et al. Adverse drug reactions as a cause of admission to hospital: prospective analysis of 18820 patients. BMJ 2004;329:15.

7 Snowden S, Nelson R. The effects of nonsteroidal anti-inflammatory drugs on blood pressure in hypertensive patients. Cardiol Rev 2011;19:184-91.

8 de Craen AJ, Di Giulio G, Lampe-Schoenmaeckers JE, Kessels AG, Kleijnen J. Analgesic efficacy and safety of paracetamol-codeine combinations versus paracetamol alone: a systematic review. BMJ 1996;313:321. 
9 Fox C, Richardson K, Maidment ID, et al. Anticholinergic medication use and cognitive impairment in the older population: the Medical Research Council Cognitive Function and Ageing Study. J Am Geriatr Soc 2011;59:1477-83.

10 Myint PK, Fox C, Kwok CS, Luben RN, Wareham NJ, Khaw KT. Total anticholinergic burden and risk of mortality and cardiovascular disease over 10 years in 21636 middle aged and older men and women of EPIC-Norfolk prospective population study. Age Ageing 2015;44:219-25.

11 NHS England, Public Health England. Advice for prescribers on the risk of misuse of pregabalin and gabapentin. Dec 2014. www.gov.uk/government/uploads/system/uploads/ attachment_data/file/385791/PHE-NHS_England_pregabalin_and_gabapentin_advice_ Dec_2014.pdf.
12 Moore RA, Wiffen P, Derry S, Toelle T, Rice AS. Gabapentin for chronic neuropathic pain and fibromyalgia in adults. Cochrane Database Syst Rev 2014;4:CD007938.

13 Kaptchuk TJ, Friedlander E, Kelley JM, et al. Placebos without deception: a randomised controlled trial in irritable bowel syndrome. PLoS One 2010;5:e15591.

14 Bhugra D, Ventriglio A, Till A, Malhi G. Colour, culture and the placebo response. Int J Soc Psychiatry 2015;61:615-17.

Cite this as: BMJ 2015;351:h5103

(c) BMJ Publishing Group Ltd 2015 